\title{
Organophosphorus Poisoning
}

\author{
Paudyal BP' \\ 'Department of Medicine, Patan Hospital, Lalitpur
}

\section{ABSTRACT}

Acute poisoning by organophosphorus (OP) compounds is a major global clinical problem, with thousands of deaths occurring every year. Most of these pesticide poisoning and subsequent deaths occur in developing countries following a deliberate self ingestion of the poison. Metacid (Methyl parathion) and Nuvan (Dichlorovos) are commonly ingested OP pesticides; Dimethoate, Profenofos, and Chlorpyrifos are other less frequently ingested compounds in Nepal. The toxicity of these OP pesticides is due to the irreversible inhibition of acetylcholinesterase (AChE) enzyme leading to accumulation of acetylcholine and subsequent over-activation of cholinergic receptors in various parts of the body. Acutely, these patients present with cholinergic crisis; intermediate syndrome and delayed polyneuropathy are other sequel of this form of poisoning. The diagnosis depends on the history of exposure to these pesticides, characteristic manifestations of toxicity and improvements of the signs and symptoms after administration of atropine. The supportive treatment of OP poisoning includes the same basic principles of management of any acutely poisoned patient i.e., rapid initial management of airways, breathing, and circulation. Gastric lavage and activated charcoal are routinely used decontamination procedures, but their value has not been conclusively proven in this poisoning. Atropine is the mainstay of therapy, and can reverse the life threatening features of this acute poisoning. However, there are no clear cut guidelines on the dose and duration of atropine therapy in OP poisoning. Cholinesterase reactivators, by regenerating $\mathrm{AChE}$, can reverse both the nicotinic and muscarinic effects; however, this benefit has not been translated well in clinical trials. All these facts highlight that there are many unanswered questions and controversies in the management of OP poisoning and there is an urgent need for research on this aspect of this common and deadly poisoning.

Key Words: poisoning, organophosphorus insecticides, decontamination, antidotes

\section{INTRODUCTION}

Organophosphorus (OP) compounds are used as pesticides, herbicides, and chemical warfare agents in the form of nerve gases. ${ }^{1}$ Acute poisoning by these agents is a major global clinical problem, with thousands of deaths occurring every year. ${ }^{2}$ Most of the
OP pesticide poisoning and subsequent deaths occur in developing countries following a deliberate self ingestion particularly in young, productive age group, as highly toxic pesticides are readily available at the moments of stress. ${ }^{3}$

\author{
Correspondence: \\ Dr. Buddhi P Paudyal \\ Department of Medicine \\ Patan Hospital, Lalitpur. \\ Email: buddhipaudyal@yahoo.com
}


Paudyal. Organophosphorus Poisoning

Poisoning has been a common cause of medical admissions and deaths in Nepalese hospitals. ${ }^{4-11}$ Thirtyone percent of all suicidal deaths in the country in 19992000 were due to poisoning. ${ }^{12}$ Hospital- based studies from five major hospitals across the country in 1999 2000 showed OP compounds were the most common form of poisoning comprising $52 \%$ of total cases. ${ }^{13}$ Various isolated hospital-based studies also clearly demonstrate that OP compounds occupy the greatest burden of poisoning related morbidity and mortality in Nepal. ${ }^{4}$

\section{COMPOUNDS}

Organophosphorus compounds were first developed by Schrader shortly before and during the Second World War. They were first used as an agricultural insecticide and later as potential chemical warfare agents. ${ }^{14}$ These compounds are normally esters, thiol esters, or acid anhydride derivatives of phosphorus containing acids. Of the more than 100 OP pesticides used worldwide, the majority are either dimethyl phosphoryl or diethyl phosphoryl compounds. ${ }^{15}$ Nerve gas compounds like tabun, sarin, and soman are highly potent synthetic toxic agents of this group. Commonly available dimethyl and diethyl OP compounds are listed in Table 1. Table 2 presents the commonly available OP pesticides with their brand names in Nepalese market.

Table 1. Common dimethyl and diethyl phosphoryl compounds ${ }^{17}$

\begin{tabular}{ll}
\hline Dimethyl Ops & Diethyl OPs \\
\hline Parathion & Methyl parathion \\
Diazinon & Dichlorovos \\
Chlorpyrifos & Dimethoate \\
Dichlorfenthion & Malathion \\
Coumaphos & Fenthion \\
\hline
\end{tabular}

Table 2. Common OP pesticides with their brands available in Nepal

\begin{tabular}{ll}
\hline OP pesticide & Brands available \\
\hline Methyl parathion & Metacid, Parahit, Paradol \\
Dichlorovos & Nuvan, DDVP, Nudan, Suchlor \\
Dimethoate & Rogor, Roger, Rogohit \\
Chlorpyrifos & Durmet, Dhanuban, Radar \\
Fenthion & Dalf, Baytex \\
Profenofos & Current \\
Quinalphos & Krush \\
Monocrotophos & Phoskill \\
\hline
\end{tabular}

Hospital-based data from across the country show that Methyl-parathion, Dichlorovos, Dimethoate, Chlorpyrifos and Malathion are the common OPs related with human poisoning. 'Metacid', a popular brand for Methyl parathion is the most frequently ingested and probably the most toxic organophosphate used for poisoning in Nepal. Dichlorovos, or 'Nuvan' as it is commonly known, is moderately volatile solution; its use has been on rise for self harm in recent years. ${ }^{4}$ Dimethoate has a lethal dose of $10-12 \mathrm{gm}$ and there are concerns that it causes specific cardiac toxicities in addition to cholinergic syndrome. Malathion is relatively less-toxic and is used for the treatment of pediculosis and scabies in humans; and has a lethal dose is $1 \mathrm{gm} / \mathrm{kg}$ in mammals. ${ }^{16}$

\section{MECHANISIM OF TOXICITY}

The toxic mechanism of OP compounds is based on the irreversible inhibition of acetylcholinesterase due to phosphorylation of the active site of the enzyme. This leads to accumulation of acetylcholine and subsequent over-activation of cholinergic receptors at the neuromuscular junctions and in the autonomic and central nervous systems. The rate and degree of AChE inhibition differs according to the structure of the OP compounds and the nature of their metabolite. In general, pure thion compounds are not significant inhibitors in their original form and need metabolic activation (oxidation) in vivo to oxon form. For example, parathion has to be metabolized to paraxon in the body so as to actively inhibit AChE. ${ }^{17}$ The toxic mechanism of OP pesticides differs from that of carbamates which inhibit the same enzyme reversibly and are sometimes useful as medicines (neostigmine, pyridostigmine) as well as insecticides (carbaryl). ${ }^{18}$

After the initial inhibition and formation of AChEOP complex two further reactions are possible: (1) Spontaneous reactivation of the enzyme may occur at a slow pace, much slower than the enzyme inhibition and requiring hours to days to occur. The rate of this regenerative process solely depends on the type of OP compound: spontaneous reactivation half life of 0.7 hours for dimethyl and 31 hours for diethyl compounds. In general, AChE-dimethyl OP complex spontaneously reactivate in less than one day whereas AChE-diethyl OP complex may take several days and reinhibition of the newly activated enzyme can occur significantly in such situation. The spontaneous reactivation can be hastened by adding nucleophilic reagents like oximes, liberating more active enzymes. These agents thereby act as an antidote in OP poisoning. ${ }^{19}$

(2) With time, the enzyme-OP complex loses one alkyl group making it no longer responsive to reactivating agents. This progressive time dependent process 
Paudyal. Organophosphorus Poisoning

is known as ageing. The rate of ageing depends on various factors like $\mathrm{pH}$, temperature, and type of OP compound; dimethyl OPs have ageing half life of 3.7 hours whereas it is 33 hours for diethyl OPs. ${ }^{20,21}$ The slower the spontaneous reactivation, the greater the quantity of inactive AChE available for ageing. Oximes, by catalyzing the regeneration of active AChE from enzyme-OP complex, reduce the quantity of inactive AChE available for ageing. Since ageing occurs more rapidly with dimethyl OPs, oximes are hypothetically useful before 12 hours in such poisoning. ${ }^{19}$ However, in diethyl OP intoxication they may be useful for many days.

\section{Clinical manifestations}

\section{Acute Cholinergic Crisis}

The clinical features of acute OP poisoning reflect the degree of accumulation of acetylcholine ( $A C h$ ) causing excessive stimulation of cholinergic receptors at various organs (acute cholinergic crisis). Acetylcholine is the principle neurotransmitter in various synapses in the human body: parasympathetic nervous system, autonomic ganglia, neuromuscular junction and central nervous system. Owing to the widespread distribution of cholinergic neurons in central and peripheral nervous

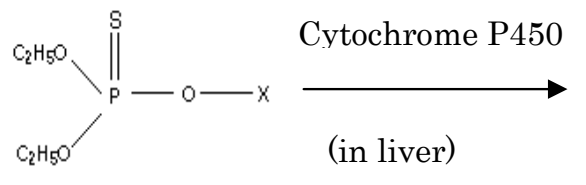

Inactive OP ('thion')

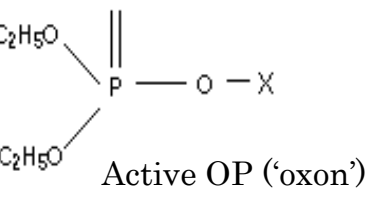

$+\mathrm{AChE}$

Spontaneous

$\mathrm{AChE}$

(Regenerated enzyme)

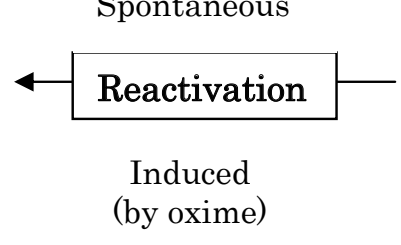<smiles>C[n+]1ccccc1/C=N\O</smiles>

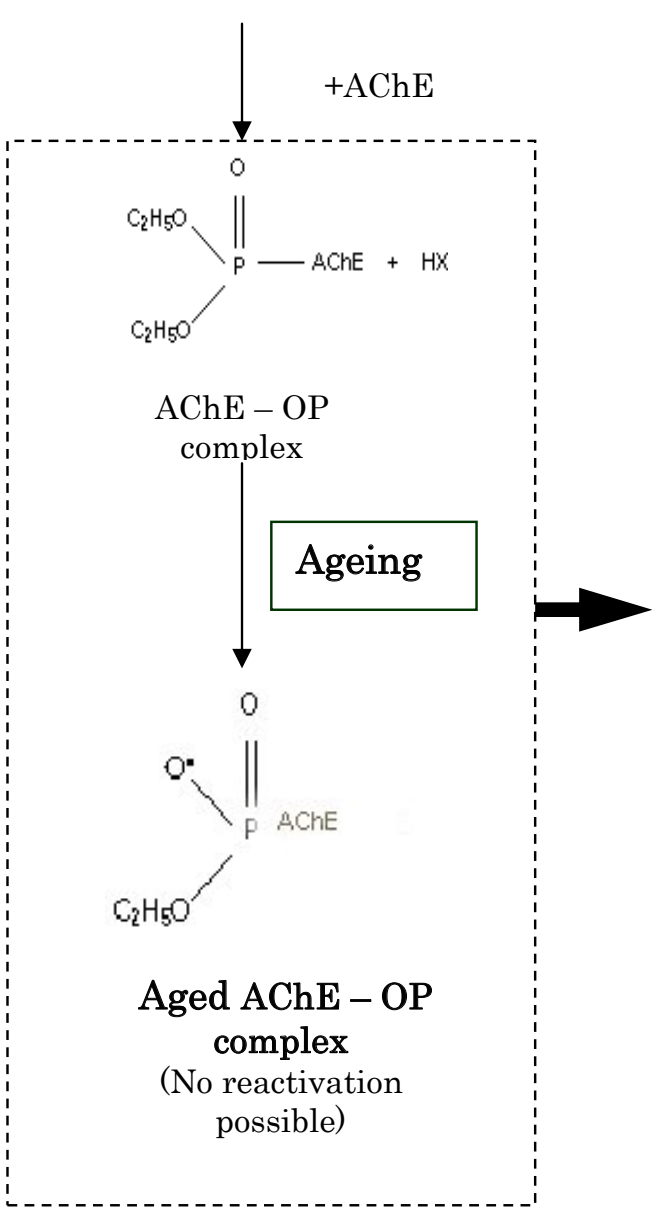

Cholinergic signs and symptoms

Figure 1. Diagrammatic representation of the possible reactivation \& ageing reactions of AChE after inhibition by OP compounds 
Paudyal. Organophosphorus Poisoning

systems, the signs and symptoms involve various organ systems. Depending on the severity of the exposure, the spectrum of the clinical presentation varies: the signs and symptoms may be mild, moderate or severe. On the basis of the receptor stimulation, the acute manifestations can be broadly divided into muscarinic, nicotinic, and central nervous system (CNS) effects. The important practical significance of this classification is that atropine only blocks muscarinic effects whereas oximes reverse both the nicotinic and muscarinic effects by reactivating $\mathrm{AChE}$ at both receptor sites because of their ability to reactivate inhibited $\mathrm{AChE}$ regardless of receptor type.

Excess $\mathrm{ACh}$ in muscarinic receptors lead to increased bronchial secretions, excessive sweating, salivation, lacrimation, miosis, bronchospasm, abdominal cramps, vomiting, involuntary passage of stool and urine. Cardiac manifestations comprise bradycardia, hypotension and QT prolongation with development of various types of arrythmias. ${ }^{22}$ Various mnemonics have been used to describe the muscarinic signs of OP poisoning: DUMBELS (diarrhoea, urination, miosis, bronchospasm, emesis, lacrimation, and salivation) and SLUDGE (salivation, lacrimation, urine incontinence, diarrhoea, gastrointestinal cramps and emesis) are commonly used ones. Stimulation of the nicotinic receptors at muscle end plate results in twitching, fasciculation, muscle weakness and flaccid paralysis; whereas stimulation of sympathetic ganglia leads to hypertension and tachycardia. Heart rate and blood pressure can be potentially misleading findings as increase or decrease can occur in both vital signs. CNS manifestations include headache, dizziness, tremor, restlessness, anxiety, confusion, convulsion and coma. Patients can also develop pancreatitis, hypo or hyperglycaemia and acute renal failure during this phase.

The time of death after a single acute exposure may range from less than five minutes to nearly 24 hours depending upon the dose, route of administration, agent and availability of treatment. ${ }^{23}$ Respiratory failure and hypotension are the main causes of death in acute stage. Delay in discovery and transport, insufficient respiratory management, aspiration pneumonia and sepsis are common causes of death. ${ }^{25}$ Prognosis in acute poisoning may depend upon many factors like dose and toxicity of the ingested OP (e.g., neurotoxicity potential, half life, rate of ageing, pro-poison or poison), and whether dimethyl or diethyl compound. ${ }^{24}$

Intermediate syndrome

The intermediate syndrome is a distinct clinical entity that usually occurs 24 to 96 hours after the ingestion of an OP compound; after an initial cholinergic crisis but before the expected onset of delayed polyneuropathy. ${ }^{25}$ Approximately $10-40 \%$ of patients treated for acute poisoning develop this illness. ${ }^{26,27}$ This syndrome is characterized by prominent weakness of neck flexors, muscles of respiration and proximal limb muscles. Though originally seen with fenthion, dimethoate and monocrotophos, it is also seen in other OP compounds. The muscle weakness in intermediate syndrome may

Table 3. Summary of clinical features and antidotes in Acute Cholinergic Crisis

\begin{tabular}{|c|c|c|c|c|}
\hline & Muscarinic features & Nicotinic features & & CNS \\
\hline & $\begin{array}{l}\text { Parasympathetic } \\
\text { (Muscarinic receptor) }\end{array}$ & NMJ (NM receptor) & $\begin{array}{l}\text { Symp Ganglia } \\
\text { (NN receptor) }\end{array}$ & $\begin{array}{l}\text { Muscarinic + ?NN } \\
\text { receptor }\end{array}$ \\
\hline Receptor Locations & $\begin{array}{l}\text { Respiratory tract } \\
\text { Gastrointestinal tract } \\
\text { Cardiovascular system } \\
\text { Exocrine glands } \\
\text { Urinary bladder }\end{array}$ & $\begin{array}{l}\text { Neuromuscular } \\
\text { junction (NMJ) of } \\
\text { striated muscles }\end{array}$ & $\begin{array}{l}\text { Paravertebral } \\
\text { sympathetic } \\
\text { ganglia and } \\
\text { Adrenal medulla }\end{array}$ & $\begin{array}{l}\text { Various parts of the } \\
\text { brain }\end{array}$ \\
\hline Dangerous effects & $\begin{array}{l}\text { Bronchospasm, } \\
\text { Pulmonary oedema } \\
\text { Diarrhoea, Vomiting, } \\
\text { Abdominal cramps } \\
\text { Bradycardia, Hypotension, } \\
\text { Ventricular tachycardia } \\
\text { Excessive secretions } \\
\text { Urinary incontinence }\end{array}$ & $\begin{array}{l}\text { Muscle weakness, } \\
\text { Paralysis, } \\
\text { Respiratory failure }\end{array}$ & $\begin{array}{l}\text { Hypertension } \\
\text { Tachycardia }\end{array}$ & $\begin{array}{l}\text { Restlessness } \\
\text { Seizures } \\
\text { Coma } \\
\text { Respiratory and } \\
\text { circulatory depression }\end{array}$ \\
\hline Antidote & $\begin{array}{l}\text { Atropine } \\
\text { Oximes }\end{array}$ & Oximes & ?Oximes & $\begin{array}{l}\text { ?Atropine } \\
\text { ? Diazepam }\end{array}$ \\
\hline
\end{tabular}


Paudyal. Organophosphorus Poisoning

last up to 5-14 days and the condition regresses slowly if respiratory support is available. Though the exact pathogenesis of intermediate syndrome is unclear, the proposed mechanisms include persistent inhibition of AChE leading to functional paralysis of neuromuscular transmission, muscle necrosis, and oxidative free radical damage to the receptors. ${ }^{28,29}$

\section{DELAYED POLYNEUROPATHY}

Delayed polyneuropathy is an uncommon consequence of severe intoxication or intermittent and chronic contact with OP pesticides as in occupational exposure. ${ }^{30}$ It is due to inhibition of neuropathy target esterase (NTE) enzyme in nervous tissues by certain OP compounds. Many locally available OPs have negligible NTE inhibitory effect except chlorpyrifos which causes intermediate degree of inhibition. Delayed polyneuropathy is often unrecognized in humans and many times the clinical features are easily overlooked. Clinical manifestations are of distal symmetric sensory-motor polyneuropathy (distal weakness, parasthesia, ataxia, diminished or absent reflexes). The symptoms usually begin 2-5 weeks after exposure to the chemical, and may last for years. ${ }^{17}$ Apart from these well-defined neural syndromes, OP pesticides can also cause chronic neurotoxicity and behavioural impairment in some patients.

\section{DIAGNOSIS}

The diagnosis of OP poisoning depends on the history of exposure to OP compounds, characteristic manifestations of toxicity and improvements of the signs and symptoms after administration of atropine. ${ }^{22}$ Diagnosis may be aided by insisting that the patient party send someone home to search for a possible poison container in the vicinity of the patient's quarters.

Garlic-like smell is an added clinical sign especially if the patient has ingested sulphur containing OP compound. Analytical identification of OP compound in gastric aspirate or its metabolites in the body fluids gives the clue that patient has been exposed to OP compound. Usually the level of plasma (pseudo) cholinesterase drops to less than $50 \%$ before signs and symptoms appear. Clinical severity has been graded on the basis of the pseudocholinesterase level (mild 20-50\% enzyme activity, moderate $10-20 \%$ enzyme activity and severe $<10 \%$ enzyme activity) ${ }^{31}$ though many believe that the enzyme activity does not correlate well with clinical severity. On the other hand, true or erythrocyte cholinesterase correlates well with clinical severity but is not available in most centres, especially in developing countries.

These laboratory tests are of limited value in acute situation because treatment is usually required before test results are available. However in doubtful cases and especially if laboratory facilities are not available, $1 \mathrm{mg}$ atropine can be given intravenously. If this does not produce marked anticholinergic manifestations, anticholinesterase poisoning should be strongly suspected. ${ }^{32}$

\section{TREATMENT}

\section{General supportive treatment}

The supportive treatment of OP poisoning follows the basic principles of management of any acutely poisoned patient. Rapid initial assessment of airways, breathing, and circulation is essential. Comatose or vomiting patients should be kept in lateral, preferably head down position with neck extension to reduce the risk of aspiration. Patent airway should be secured with proper positioning, placement of Guedel's airway or with endotracheal intubation especially if the patient is unconscious, fitting, or vomiting. Frequent suctioning is essential as excessive oropharyngeal and respiratory secretions may occlude the airway. Oxygen is needed in majority of these patients; and this can be assessed by frequent assessment of arterial oxygen saturation.

The skin and clothes of these patients are frequently contaminated with poison and vomiting. The clothes should be removed and the skin vigorously washed with soap and water. People involved in first aid should wear rubber gloves so as to prevent skin absorption of the poison.

Gastric lavage may help to reduce the absorption of the ingested poison and should be considered in patients presenting within 1-2 hours of ingestion of poison. The risks of gastric lavage include aspiration, hypoxia, and laryngeal spasm, and these can be reduced with proper management of airway. ${ }^{33,34}$ The induction of vomiting with soap water, ipecacuanha or other agents may cause more harm than benefit as many OPs are dissolved in petroleum distillates and can cause severe pneumonitis and acute respiratory distress syndrome when aspirated. ${ }^{35}$ Use of home remedies like ingestion of milk may dilute the poison but risks increased gastric emptying; and 'pushing' the poison into small bowel from where it is readily absorbed with early development of toxicity. On the contrary small amount of lipid-rich home remedy (e.g. raw eggs) may slow gastric emptying and delay the onset of poisoning and respiratory failure. ${ }^{36}$ Cathartics may further aggravate the OP-induced diarrhea leading to dehydration and electrolyte imbalance; therefore their use can not be recommended in routine practice.

Activated charcoal helps to reduce the poison load by adsorbing it; and this has been clearly shown to 
Paudyal. Organophosphorus Poisoning

be effective in OP poisoning in animal experiment. ${ }^{37}$ Though its efficacy has not been conclusively proven in humans, single to multiple dose activated charcoal is routinely used in clinical practice. An ongoing randomized controlled trial in Sri Lanka comparing single or multiple dose activated charcoal versus placebo in OP poisoning may settle this issue. ${ }^{38}$

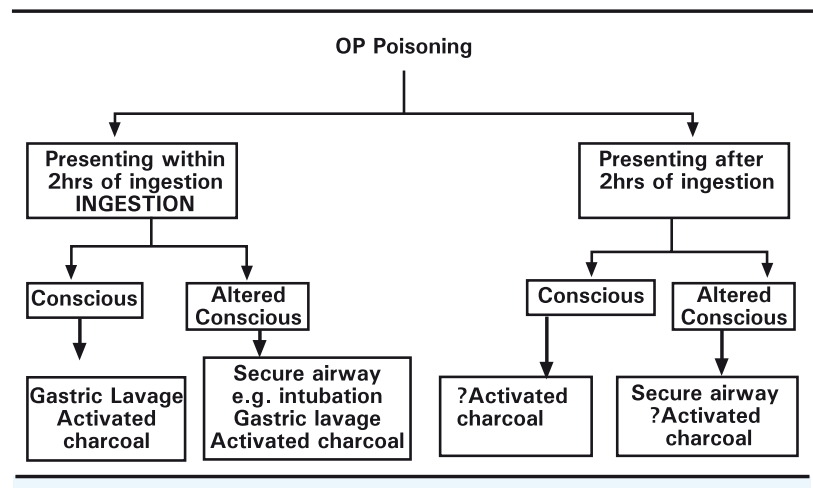

Figure 2. Decontamination Procedure in OP Poisoning

Specific Antidotal Treatment

Atropine: Atropine has been the cornerstone in the management of OP poisoning for decades and will remain so in the future. It acts competitively at the peripheral and central muscarinic receptors and antagonizes the parasympathetic effects of excess $\mathrm{ACh}$ at these sites. It reverses life threatening features from poisoning; delay or inadequate atropine can result in death from central respiratory depression, bronchospasm, excessive bronchosecretion, severe bradycardia, and hypotension. $^{2}$

There are wide variations in recommended doses and regimens of atropine therapy in different parts of the world. Moreover, duration of atropine treatment and titration of the dose is not clear. Current guidelines recommend the use of bolus doses to attain target endpoints, followed by setting up an infusion to maintain these end-points. ${ }^{24}$

Target end-points for Atropine therapy ${ }^{39}$

Heart rate $>80 /$ min

Dilated pupils

Dry axillae

Systolic blood pressure $>80 \mathrm{~mm} \mathrm{Hg}$

Clear chest with absence of wheeze

We use an initial bolus of 3-5 ampoules of atropine (each ampoule containing $0.6 \mathrm{mg}$ ) with subsequent doses doubled every 5 minutes until atropinization is achieved. ${ }^{39}$ When the patient achieves most of (at least 4 out of 5) the target end-points for atropine therapy i.e., 'fully atropinized', an intravenous infusion is set up to maintain the therapeutic effects of atropine. While there are different approaches of atropine infusion, we use $20 \%$ of initial atropinizing dose per hour for first 48 hours and gradually taper over 5 -10 days, continuously monitoring the adequacy of therapy.

There is a tendency to give excess atropine, which can be dangerous. Atropine toxicity can result in agitation, confusion, hyperthermia, and severe tachycardia that can precipitate ischaemic events in patients with underlying coronary artery disease. ${ }^{2}$ So, close observation and dose adjustment is essential to avoid the features of both under- and over-atropinization.

Some centres use another anticholinergic agent glycopyrrolinium bromide along with atropine in order to limit the central stimulation produced by atropine, because the former does not cross blood brain barrier. ${ }^{36}$

Oximes: Oximes work by reactivating acetylcholinesterase that has been bound to the OP molecule. Pralidoxime is the most frequently used oxime worldwide; other members of the class include obidoxime, and experimental HI 6 and HLO 7. Oximes can be highly effective in restoring skeletal muscle strength and improving diaphragmatic weakness where atropine has virtually no effect. ${ }^{23}$

Notwithstanding this theoretical advantage, clinical opinions of oxime therapy in OP poisoning are divided, even in cases of massive human intoxication. ${ }^{40}$ Outcomes following oxime therapy depend on various factors like the type of poison ingested, the poison load, time elapsed between OP ingestion and institution of therapy, and the duration and dosage of the oxime therapy. In some cases oximes may prove ineffective for several reasons: inadequate dose leading to subtherapeutic blood levels, early termination of oxime therapy, and continuous reinhibition of the reactivated AChE from pesticide persisting in the body. ${ }^{23}$ The therapeutic window for oximes is limited by the time taken for 'ageing' of the enzyme-OP complex, because 'aged' enzyme can no longer be reactivated by oximes (see mechanism of toxicity, above).

However, others propose prolonged maintenance of an appropriate oxime concentration irrespective of the type of ingested OP. ${ }^{41}$ Some advise oxime therapy for the treatment of intermediate syndrome. ${ }^{42}$

Various dosage regimens have been recommended from intermittent oxime administration to continuous infusion following a loading dose. While there is no clear consensus on the dose and duration of oxime therapy, recently the WHO recommended pralidoxime dose of $30 \mathrm{mg} / \mathrm{kg}$ bolus iv followed by continuous infusion of 
Paudyal. Organophosphorus Poisoning

$8 \mathrm{mg} / \mathrm{kg} /$ hour until clinical improvement. ${ }^{39}$ Dizziness, headache, blurred vision, and diplopia, are common side effects of oxime therapy. Rapid administration may lead to tachycardia, laryngospasm, muscle spasm, and transient neuromuscular blockade. ${ }^{16}$ Difficult availability and cost factor are other drawbacks for routine use of oximes in clinical practice.

Benzodiazepines: Diazepam and other benzodiazepines are widely used for the treatment of OP induced seizures and restlessness and agitation consequent to either poison itself or sequel of atropine therapy.

39 Moreover diazepam, due to its central respiratory depressant action, is also believed to attenuate OPinduced respiratory depression which usually follows overstimulation of the CNS respiratory centers. ${ }^{1}$

\section{PREGNANCY}

Pregnant patients who have ingested OP insecticides during the second or third trimester of pregnancy have been treated successfully with atropine and pralidoxime and later delivered healthy newborns with no significant abnormalities. ${ }^{43}$ However, foetal distress is a possible complication of both of the poisoning as well as its treatment. ${ }^{16}$

\section{Newer forms of therapies in OP poisoning}

One small uncontrolled study from Iran concluded that the infusion of sodium bicarbonate significantly reduced total hospital stay, total atropine requirement, and the need for intensive care therapy; mortality rate was also low in the treatment group. ${ }^{44}$ Adrenergic receptor $a 2$ agonists like clonidine inhibit the release of $\mathrm{ACh}$ from cholinergic neurons and may decrease the excess $\mathrm{ACh}$ at synaptic cleft. Though animal studies have shown improved survival with clonidine in OP poisoning, human studies are yet to be done. ${ }^{45}$ Magnesium sulphate, ${ }^{46}$ fresh frozen plasma, ${ }^{47}$, antioxidants, 48 Organophosphorus hydrolases, 49 and galyclidine (NMDA receptor antagonist) ${ }^{50}$ are all potential forms of therapies for the future. ${ }^{46-50}$

\section{ACKNOWLEDGEMENT}

The authors would like to thank Mr. Macha Bhai Shakya for his help during the preparation of this manuscript.

\section{REFERENCES}

1. Bowls BJ, Freeman JM, Luna JA, Meggs JA. Oral treatment of Organophosphate poisoning in mice. Acad Emerg Med 2003;10:286-87.

2. Eddleston M, Buckley NA, Checketts H, Senarathna L, Mohamed F, Rezvi Sheriff MH et al. Speed of Initial Atropinization in Significant Organophosphorous Pesticide Poisoning- A Systematic Comparison of Recommended Regimens. J Toxicol Clin Toxicol 2004;42:865-75.

3. Karalliedde L, Eddleston M, Murray V. The global picture of organophosphate poisoning. In: Karalliedde L, Feldman F, Henry J, et al. eds. Organophosphates and health. London: Imperial Press; 2001. p. 432-71.

4. Paudyal BP. Poisoning: Pattern and Profile of Admitted Cases in a Hospital in Central Nepal. J Nep Med Assoc 2005;44:9296

5. Kafle KK, Gyawali KK. Organophosphorus- Commonest Poisoning Agent. J Inst Med 1992; 14: 228-233

6. Prasad PN, Karki P. Poisoning cases at TUTH emergency; a one-year review. J Inst Med 1997; 19: 18-24

7. Ghimire RH, Sharma SP, Pandey KR. A Retrospective Study of the Changing Trends of Poisoning Cases at Tribhuvan University Teaching Hospital, Nepal Between 1990-1992 and 2000-2002. J NHRC

8. Subedi BK. A Retrospective Study of Poisoning Cases at Bir Hospital, Nepal. J Inst Med 1990; 12: 296-302

9. Pokhrel N, Gurung CK. A Study of Poison Cases Recorded in Bir Hospital Over Four Years. J Inst Med 1987; 29-34
10. Rauniyar GP, Das BP, Naga Rani MA, Gupta MP, Karki BMS. Retrospective Analysis of Profile of Acute Poisoning Cases in a Tertiary Care Hospital in Eastern Nepal: A Four-Year Database from 1994 to 1997. J Nep Med Assoc 1999; 38: 23-28

11. Pathak UN, Chhetri PK, Dhungel S, Chokhani R, Devkota KC, Shrestha BO et al. Retrospective Study of Poisoning Cases Admitted in Nepal Medical College Teaching Hospital. Nep Med Col J 2001; 3: 101-5

12. His Majesty's Government of Nepal. Central Bureau of Statistics, National Planning Commission. Statistical Year Book of Nepal. 2001.

13. Gupta SK, Joshi MP. Pesticide Poisoning Cases Attending Five Major Hospitals of Nepal. J Nep Med Assoc 2002;41:447-56.

14. Taylor P. Anticholinesterase agents. In: Goodman and Gilman's The Pharmacological Basis of Therapeutics. Ed. Hardman JG, Limbird LE, Molinoff PB, Ruddon RW. 9th ed. 1996. P. 161-76.

15. WHO Task Group on Organophosphorus Insectides. Organophosphorus insecticides: A general introduction. WHO, Geneva 1986.

16. Ellenhorn MJ. Ellenhorn's Medical Toxicology. 2nd ed. 1997. P. 1614-1631.

17. Johnson MK, Jacobsen D, Meredith TJ, Eyer P, Heath AJ, Ligtenstein DA et al. The IPCS working group on antidotes for organophosphorus pesticide poisoning, WHO. Evaluation of antidotes for poisoning by organophosphorus pesticides. Emerg Med 2000;12:22-37. 
18. Tripathi KD. Essentials of Medical Pharmacology. 4th ed. Jaypee Brothers, 1999. p. 89.

19. Eddleston M, Szinicz L, Eyer P, Buckley N. Oximes in acute organophosphorus pesticide poisoning: a systematic review of clinical trials. Q J Med 2002;95:275-83.

20. Worek F, Backer M, Thierman H, et al. Reappraisal of indications and limitations of oxime therapy in organophosphate poisoning. Hum Exp Toxicol 1997;16:46672 .

21. Worek F, Diepold C, Eyer P. Dimethylphosphoryl-inhibited human cholinesterases: inhibition, reactivation and ageing kinetics. Arch Toxicol 1999;73:7-14.

22. Karki P, Ansari JA, Bhandary S, Koirala S. Cardiac and electrocardiographical manifestations of acute organophosphate poisoning. Singapore Med J 2004;45:38589.

23. Eyer P. The Role of Oximes in the Management of Organophosphorus Pesticide Poisoning. Toxicol Rev 2003;22:165-90.

24. Munidasa UADD, Gawarammana IB, Kulratne SAM, Kumarasiri PVR, Goonasekera CDA. Survival Pattern of Patients with Acute Organophosphate Poisoning Receiving Intensive Care. J Toxicol Clin Toxicol 2004;42:343-47.

25. Senanayake N, Karalliedde L. Neurotoxic effects of organophosphorus insecticides. An intermediate syndrome. N Engl J Med 1987;316:761-63.

26. De Bleeker J, van den Neucker K, Colardyn F. Intermediate syndrome in organophosphate poisoning: A prospective study. Crit Care Med 1993;21:1706-11.

27. He F, $\mathrm{Xu} \mathrm{H}$, Qin $\mathrm{F}, \mathrm{Xu} \mathrm{L}$, Huang J, He X. Intermediate myasthenia syndrome following acute organophosphate poisoning: An analysis of 21 cases. Hum Exp Toxicol 1998;17:40-45.

28. Karalliedde L, Henry JA. Effects of organophosphates on skeletal muscles. Hum Exp Toxicol 1993;12:289-96.

29. John M, Oommen A, Zachariah A. Muscle injury in Organophosphorus poisoning and its role in the development of Intermediate Syndrome. Neurotoxicology 2003;24:43-53.

30. Moretto A, Lotti M. Poisoning by organophosphorus insectides and sensory neuropathy. J Neurol Neurosurg Psychiatry 1998;64:463-8.

31. Proudofoot A. Organophosphate and carbamate insectides. In: Diagnosis and management of Acute Poisoning. 1st ed. Oxford: Blackwell Scientific 1982:153-7.

32. Gorkhaly MP. Organophosphorus Poisoning- An Update. Postgrad Med J Nep 2001;2:63-68.

33. American Academy of Clinical Toxicology, European Association of Poison Centres and Clinical Toxicologists. Position statement: gastric lavage. J Toxicol Clin Toxicol 1997;35:721-41.

34. Eddleston M, Juszczak E, Buckley N. Does gastric lavage really push poisons beyond the pylorus? A systematic review of the evidence. Ann Emerg Med 2003;42(3):359-64

35. American Academy of Clinical Toxicology, European
Association of Poison Centres and Clinical Toxicologists. Position statement: ipecac syrup. J Toxicol Clin Toxicol 1997;35:699-709.

36. Eddleston M, Singh S, Buckley N. Organophosphorus poisoning (acute). Clin Evid 2004;12:1-15.

37. Tuncock Y, Gelal A, Apayadin S, et al. Prevention of oral dichlorovos toxicity by different activated charcoal products in mice. Ann Emerg Med 1995;25:353-5.

38. Dawson A. SACTRC Agrochemical Workshop. Colombo, Sri Lanka. Aug 2005.

39. Eddleston M, Dawson A, Karalliedde L, Dissanayake W, Hittarage A, Azher $S$ et al. Early management after selfpoisoning with an organophosphorus or carbamate pesticide - a treatment protocol for junior doctors. Crit Care 2004;8: R391-R397.

40. DeSilvaHJ,WijewickremaR,SenanayakeN. Does pralidoxime affect outcome of management in acute Organophosphorus poisoning. Lancet 1992;339:1136-8.

41. De Cort WLAM, Kiestra SH, Sangster B. The role of atropine and oximes in organophosphate intoxication: a modified approach. J Toxicol Clin Toxicol 1988;26:199-208.

42. Besser R, Weileman LS, Gutman L. Efficacy of obidoxime in human organophosphorus poisoning: Determination by neuromuscular transmission studies. Muscle Nerve 1995;18:15-22.

43. Karalliedde L, Senanayake N, Ariaaratnam A. Acute organophosphorus insectide poisoning during pregnancy. Hum Toxicol 1988;7:363-64.

44. Balali-Mood M, Mohammed-Hossain A, Hasan A. Effect of high doses of sodium bicarbonate in acute Organophosphorus pesticide poisoning. Paper presented in SACTRC workshop, August 2004, Colombo, Sri Lanka.

45. Liu WF. A symptomatological assessment of organophosophate-induced lethality in mice: comparison of atropine and clonidine protection. Toxic Lett 1991;56:19-32.

46. Pajoumand A, Shadnia S, Rezaie A, Abdi M, Abdollahi M. Benefits of magnesium sulphate in the management of acute human poisoning by organophosphorus insecticides. Hum Exp Toxicol 2004;23:565-69.

47. Guven M, Sungur M, Eser B, Sart I, Fezvi A. The effects of Fresh Frozen Plasma on Cholinesterase Levels and Outcomes in Patients with Organophosphate Poisoning. J Toxicol Clin Toxicol 2004;42;617-23.

48. Ranjbar A, Solhi H, Mashayekhi FJ, Susanabdi A, Rezaie A, Abdollahi M. Oxidative stress in acute human poisoning with organophosphorus insectides: a case control study. Environ Toxicol Pharmacol 2005;20:88-91.

49. Sogorb MA, Vilanova E, Carrera V. Future applications of phosphotriesterases in the prophylaxis and treatment of organophosphorus insectide and nerve agent poisoning. Toxicol Lett 2004;151:219-33.

50. Lallement G, Baubicohn D, Clarencon D, et al. Review of the value of galyclidine (GK-11) as adjuvant medication to conventional treatments of organophosphate poisoning: primate experiments mimicking various scenarios of military or terrorist attack by soman. Neurotoxicology 1999;20:67584. 